\title{
Expression of CXCR-4 and IDO in human colorectal cancer: An immunohistochemical approach
}

\author{
MASAICHI OGAWA, MICHIAKI WATANABE, TAKUO HASEGAWA, KOHEI ICHIHARA, \\ KAZUHIKO YOSHIDA and KATSUHIKO YANAGA
}

Department of Surgery, The Jikei University School of Medicine, Tokyo 105-8461, Japan

Received July 27, 2016; Accepted February 8, 2017

DOI: $10.3892 /$ mco.2017.1207

\begin{abstract}
C-X-C chemokine receptor type 4 (CXCR4), the receptor for the chemokine stromal cell-derived factor (SDF)-1 [also known as C-X-C motif chemokine 12 (CXCL12)], is involved in lymphocyte trafficking. Recent studies have demonstrated that, during pregnancy, a placental enzyme called indoleamine 2, 3-dioxygenase (IDO) exerts a key role in suppressing the maternal T-cell response against the fetus. In the present study, the significance of CXCR4 and IDO expression in human colorectal cancer (CRC) has been investigated by immunohistochemical assay, and their association with survival was analyzed. Tumor specimens $(n=60)$ from patients with different American Joint Committee on Cancer (AJCC) stages of CRC (I or IV) were assessed. In the stage IV group, 23 of 30 cases (77\%) stained positive for CXCR4, and 9 of 30 (30\%) were positive for IDO. By contrast, in the stage I group, 7 of 30 cases (23\%) stained positive for CXCR4, and 15 of 30 cases (50\%) were positive for IDO. The 5 -year survival rate of those with high CXCR4 expression in tumor specimens $(\mathrm{n}=30)$ was significantly worse compared with those with negative CXCR4 expression (16.3 vs. 60.7\%, $\mathrm{P}=0.02$ ). By contrast, the 5-year survival rate of those with high IDO expression in tumor specimens $(n=24)$ was not significantly different compared with those with negative IDO expression (36.4 vs. 56.8\%). In the stage I group, 4 patients in the high IDO expression group $(\mathrm{n}=15)$ had distant metastases ( 2 in the liver 1 in the brain, and 1 in the lung). Taken together, CXCR4 appears to be a novel predictive indicator of survival, and IDO expression in the early stage may be a predictor of distant metastasis.
\end{abstract}

Correspondence to: Dr Masaichi Ogawa, Department of Surgery, The Jikei University School of Medicine, 3-25-8 Nishi-Shinbashi, Minato-ku, Tokyo 105-8461, Japan

E-mail: masatchmo1962@yahoo.co.jp

Keywords: C-X-C chemokine receptor type 4,CXCR-4, indoleamine 2,3-dioxygenase, colorectal cancer, immunohistochemistry

\section{Introduction}

Colorectal cancer (CRC) is the third most common cancer worldwide, and the fourth most common with respect to cancer-associated mortality (1). Surgical excision offers the only potential cure; however, tumor recurrence is comparatively common, even following $\mathrm{R} 0$ resection. The 5-year survival rate for patients with stage II CRC is $80-90 \%$, whereas that of those with stage IV is only 10-20\% (2). Clinically useful prognostic biomarkers are required to improve the outcome of patients with stage IV CRC. C-X-C chemokine receptor type 4 (CXCR4), a G-protein-coupled chemokine receptor encoded on chromosome 2 (3), exerts its biological effect by binding stromal cell-derived factor 1 (SDF-1) (4); a previous report has also demonstrated that ubiquitin is a natural ligand of CXCR4 (5). Chemokinetic functions in the immune system, chemokines and their receptors also exert critical roles in tumor initiation, progression and metastasis (6). CRC cells have been shown to express the chemokine receptors, CXCR4 and CXCR3 (7-12). In a clinical study, CXCR4 expression in CRC was revealed to increase the recurrence of the cancer, poor survival and liver metastasis (8).

In mammalian organisms, tryptophan is an essential amino acid for cell survival. Tryptophan degradation occurs via the kynurenine pathway, with the initial and rate-limiting catalyzing activity of indoleamine 2,3-dioxygenase (IDO). Initially, the role of IDO was considered to be predominantly antimicrobial in reducing the availability of tryptophan in the inflammatory environment (13-16). IDO was expressed in normal tissues, such as the endothelial cells in the placenta, the epithelial cells in the female genital tract, and the lymphoid tissues in mature dendritic cells (17). IDO occupies a central role in preventing $\mathrm{T}$ cell-driven rejection of allogeneic fetuses during pregnancy as the trophoblasts are expressed. IDO was found to induce maternal tolerance to fetal allografts (18). The role of IDO in the immune escape of tumors has been reviewed previously by Zou (19). This suggests that IDO inhibitors may exert antitumor effects by suppressing immune tolerance. IDO expression in human CRC has also been reported (20-22); however, the clinical significance of IDO expression in CRC remains a controversial topic. The aim of the present study was to evaluate the association between CXCR4, IDO and CRC. In addition, the present study also aimed to further investigate a possible prognostic role of IDO and CXCR4 expression 
in cases of CRC at stage I and IV of CRC, according to the American Joint Committee on Cancer (AJCC) staging system.

\section{Materials and methods}

Patient selection. Patients who underwent surgery for AJCC stage I or IV CRC were selected consecutively at the Department of Surgery, the Jikei University School of Medicine between January and November 2003. A total of 60 specimens were assessed from 60 patients (Table I). No stage I patients in the present cohort received any adjuvant chemotherapy, whereas all the eligible patients with stage IV CRC received fluorouracil- and leucovorin-based chemotherapy.

Immunohistochemical analysis. For the immunohistochemical study, formalin-fixed, paraffin-embedded sections were used. Immunostaining was performed using the labeled, streptavidin-biotin peroxidase complex method associated with the Ventana auto-immunostaining system (Ventana Japan, K.K., Yokohama, Japan), according to the manufacturer's protocol. Murine monoclonal antibodies against human IDO (23) (anti-IDO; dilution, 1:1,000) and against CXCR4 (anti-CXCR4, clone no. 44716; dilution, 1:200; R\&D Systems, Inc., Minneapolis, MN, USA) were used. The antigen retrieval procedure was performed in a microwave oven using DAKO ${ }^{\circledR}$ Antigen Retrieval Solution (Dako; Agilent Technologies, Inc., Santa Clara, CA, USA) for $10 \mathrm{~min}$ at $95^{\circ} \mathrm{C}$ to efficiently stain the samples. The sections (Dako Cytomation; Dako; Agilent Technologies, Inc.) were developed with 3,3'-diaminobenzidine with $0.3 \%$ hydrogen peroxide, and counterstained with hematoxylin. In all cases, normal epithelial cells were negative for CXCR4 and IDO expression. Neoplastic cells with cytoplasmic and/or membrane-localized immunohistochemical expression of CXCR4 were considered positive cells. Macrophage positivity was used as an adequate internal positive control for each case in order to validate the technical procedure. CXCR4 staining was categorized into four semiquantitative groups based on the rate of stained (positive) tumor cells: Absence of staining; $<10 \%$ positive cells (low); $10-50 \%$ positive cells (moderate); and $>50 \%$ positive cells (high) (Fig. 1). On the other hand, IDO staining was categorized into two classes: Positive or negative (Fig. 2). Slides were evaluated by two blinded observers (M.O. and M.I.); discordant cases were discussed, and a concordance of opinion was subsequently achieved.

Statistical analysis. Correlations between CXCR4 and IDO expression, baseline patient features, and tumors were studied using contingency tables and the Chi-square test. Overall survival (OS) was defined as the time that had elapsed from the date of the initial diagnosis to mortality, or to the date of the last available information on the patient's vital status. The Kaplan-Meier product limit method was applied to draw the OS curves. $\mathrm{P}<0.05$ was considered to indicate a statistically significant difference.

\section{Results}

Expression rate. In the stage I group, 7 out of 30 cases (23\%) stained positive for CXCR4, and 15 of 30 cases $(50 \%)$ were positive for IDO. In the stage IV group, 23 of 30 cases $(77 \%)$
Table I. Patients' characteristics.

\begin{tabular}{lc}
\hline Parameter & Data \\
\hline Age, years [median (range)] & $68(41-82)$ \\
Sex [no. of patients (\%)] & $36(60)$ \\
$\quad$ Male & $24(40)$ \\
Female & \\
Primary site [no. of patients (\%)] & $38(63.3)$ \\
Colon/rectosigmoid & $22(26.7)$ \\
Rectum & \\
Stage ${ }^{\text {a }}$ [no. of patients (\%)] & $30(50)$ \\
I & $30(50)$ \\
IV &
\end{tabular}

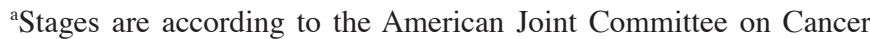
(AJCC) staging system.

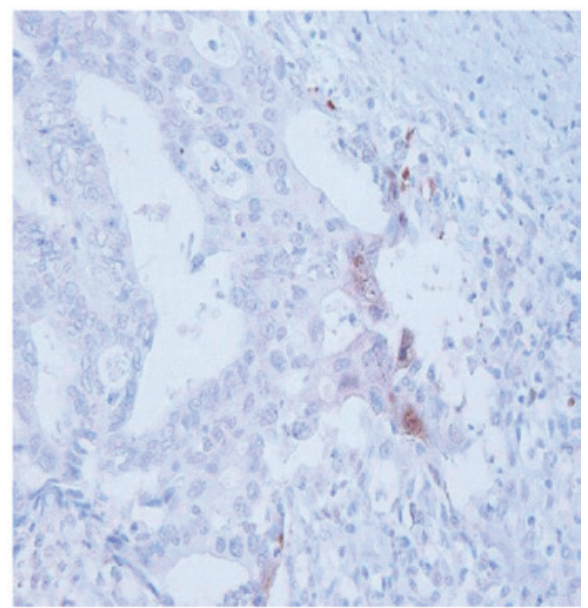

Figure 1. Neoplastic cells with immunohistochemical expression of CXCR4, located in the cytoplasm and/or the membrane, are shown. Cells that revealed immunohistochemical expression of CXCR4 were considered positive. A calculation of $10 \%$ positive cells was made, placing the number of positive cells into the 'low' category. CXCR4, C-X-C chemokine receptor type 4.

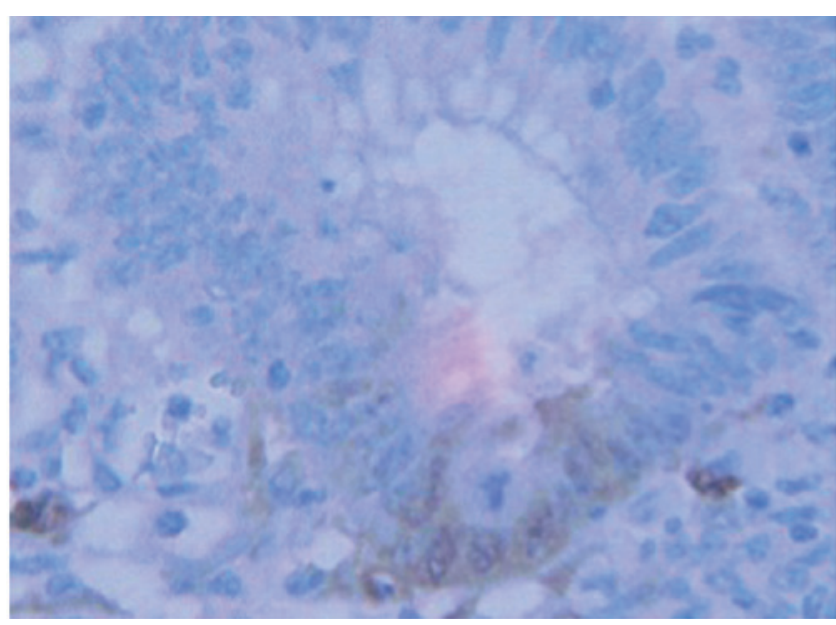

Figure 2. Cells that revealed immunohistochemical expression of IDO were considered positive. The positive cancerous cells were recognized in the submucosal layer. The case illustrated in this figure is T1 case. IDO, indoleamine 2,3-dioxygenase. 
Table II. Expression rates of CXCR4 and IDO.

\begin{tabular}{|c|c|c|c|}
\hline Stage $^{a}$ & Protein & Negative (\%) & $\begin{array}{c}\text { Positive } \\
(\text { Low/moderate/high })^{\mathrm{b}}(\%)\end{array}$ \\
\hline \multirow[t]{3}{*}{ Stage I } & CXCR4 & $23(77)$ & $7(23)$ \\
\hline & & & $(7 / 0 / 0)$ \\
\hline & IDO & $15(50)$ & $15(50)$ \\
\hline \multirow[t]{3}{*}{ Stage IV } & CXCR4 & $7(23)$ & $23(77)$ \\
\hline & & & $(7 / 3 / 13)$ \\
\hline & IDO & $21(70)$ & $9(30)$ \\
\hline
\end{tabular}

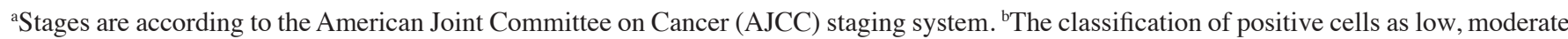
and high is only applicable for the CXCR4 data. CXCR4, C-X-C chemokine receptor type 4; IDO, indoleamine 2,3-dioxygenase

stained positive for CXCR4, and 9 of 30 cases (30\%) were positive for IDO (Table II).

Association between the 5-year survival rate and the expression levels of CXCR4 and IDO for the tumor specimens. The 5-year survival rate of those patients with a high level of CXCR4 expression in tumor specimens $(n=30)$ was significantly worse compared with those with negative CXCR4 expression (16.3 vs. $60.7 \%, \mathrm{P}=0.02$ ) (Fig. 3). The 5-year survival rate of those with high IDO expression in tumor specimens $(n=24)$ was not significantly different compared with those with negative IDO expression (36.4 vs. 56.8\%) (Fig. 4). However, in the stage I group for IDO, although none of the patients in the high IDO expression group $(n=15)$ had negative expression, 4 patients had highly distant metastases ( 2 in the liver, 1 in the brain, and 1 in the lung) (27\%: 4/15). Therefore, CXCR4 appears to be a novel predictive indicator of survival, and high IDO expression in the early stage may be a predictor of distant metastasis.

\section{Discussion}

Chemokines are structurally related, small-polypeptide signaling molecules that bind to and activate a family of G-protein-coupled receptors (22). The interaction of chemokines and CRs is crucial in promoting tumor cell proliferation, angiogenesis and migration (24-26). The chemokine receptor, CXCR4, is the first identified chemokine receptor to exert a critical role in determining the metastatic destination of breast cancer to the bone and lungs, where its ligand, C-X-C motif chemokine 12 (CXCL12), is abundant $(27,28)$. In clinical studies, the expression of CXCR4 in CRC was demonstrated to increase the recurrence of the cancer, poor survival and liver metastasis (8). The CXCR4 ligand, CXCL12, was secreted by distant metastasis, and this increased the risk of postoperative recurrence (29). The present study has demonstrated that CXCR4 was a prognostic factor of postoperative tumor progression. The high expression of CXCR4 presented a significant difference with respect to the decreased survival rate. CXCR4 has been considered as a potential therapeutic target in several studies. A number of in vitro studies have reported that inhibiting the interactions of chemokine CXCR4 using antibodies or small molecules markedly reduces the metastasis of colorectal cancer cells $(30,31)$;

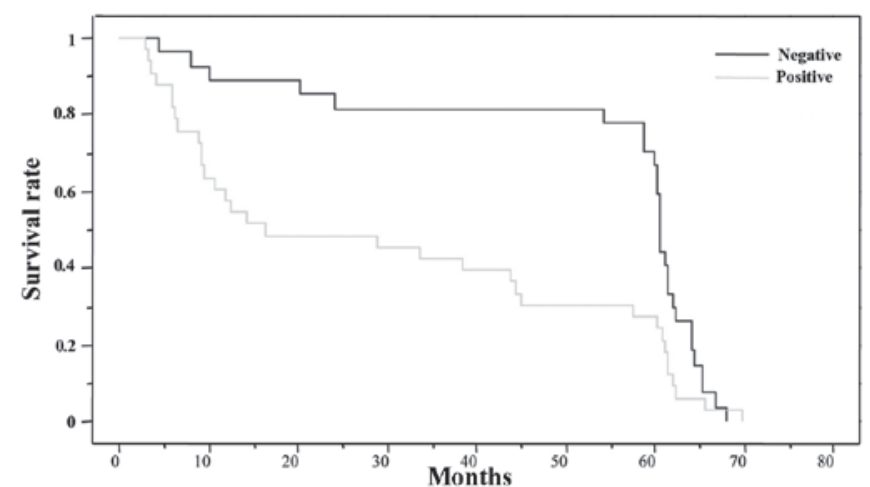

Figure 3. The 5-year survival rate of those patients with high CXCR4 expression in tumor specimens $(n=30)$ was significantly worse compared with those with negative CXCR4 expression (16.3 vs. $60.7 \%, \mathrm{P}=0.02)$.

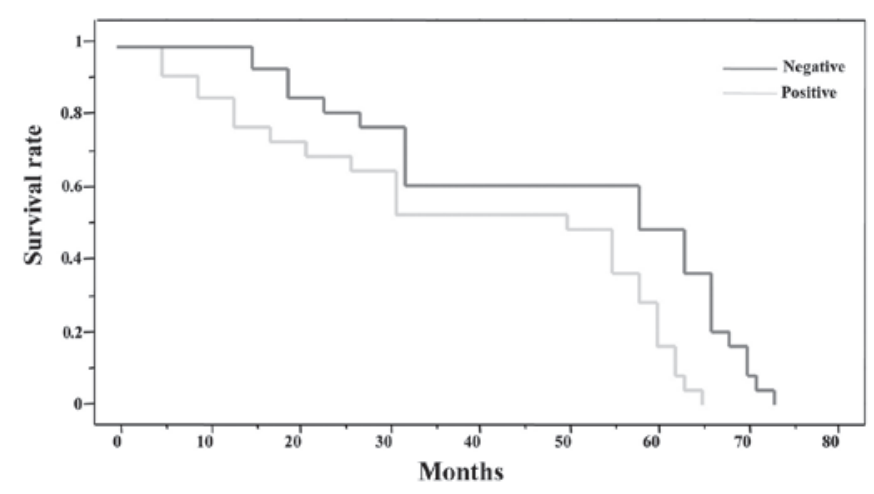

Figure 4. The 5-year survival rate of those patients with high IDO expression in tumor specimens $(n=24)$ was not significantly different compared with those with negative IDO expression (36.4 vs. 56.8\%).

this approach could become a promising therapy for colon cancer.

Uyttenhove et al (32) provided the first evidence for a tumor-immune resistance mechanism, based on tryptophan degradation in a murine model in which these authors demonstrated that the immunomodulatory enzyme, IDO, reduced anti-tumor T cell attack. Muller et al (33) stated that IDO activity in tumor cells is the relevant target for inhibition to overcome immune escape (33). Thus, it appears plausible that 
the identity of IDO-expressing cells may depend on the type of tumor. Okamoto et al (34) reported a marked association between IDO-staining patterns within tumor cells and OS in patients with serous ovarian cancer. According to the data in the present study, IDO expression significantly correlated with the distant metastases in early-stage CRC. In early-stage CRC, within the patients who expressed a high level of IDO, the initial immunological response of the host towards the primary tumor may be able to generate tolerizing conditions. As a result, IDO-expressing tumor cells may be able to stave off an immune attack. Thus, if the expression of IDO was demonstrated to be a risk factor for early-stage colon cancer, this population of cells might become a potential indicator for postoperative chemotherapy. Additional, large cohort studies in a multicenter setting are necessary to validate these findings, and to examine the potential mechanisms for ligand interactions concerning IDO and CXCR4 in CRC metastasis.

In conclusion, CXCR4 appears to be a novel predictive indicator of survival, and IDO expression in the early stages of colon cancer may be a predictor of distant metastasis.

\section{References}

1. Weitz J, Koch M, Debus J, Höhler T, Galle PR and Büchler MW: Colorectal cancer. Lancet 365: 153-165, 2005.

2. Jemal A, Murray T, Ward E, Samuels A, Tiwari RC, Ghafoor A, Feuer EJ and Thun MJ: Cancer statistics, 2005. CA Cancer J Clin 55: 10-30, 2005.

3. Caruz A, Samsom M, Alonso JM, Alcami J, Baleux F, Virelizier JL, Parmentier $M$ and Arenzana-Seisdedos F: Genomic organization and promoter characterization of human CXCR4 gene. FEBS Lett 426: 271-278, 1998.

4. Kucia M, Jankowski K, Reca R, Wysoczynski M, Bandura L, Allendorf DJ, Zhang J, Ratajczak J and Ratajczak MZ: CXCR4-SDF-1 signalling, locomotion, chemotaxis and adhesion. J Mol Histol 35: 233-245, 2004.

5. Saini V, Marchese A and Majetschak M: CXC chemokine receptor 4 is a cell surface receptor for extracellular ubiquitin. J Biol Chem 285: 15566-15576, 2010.

6. Chambers AF, Groom AC and MacDonald IC: Dissemination and growth of cancer cells in metastatic sites. Nat Rev Cancer 2 : 563-572, 2002

7. Zeelenberg IS, Ruuls-Van Stalle L and Roos E: The chemokine receptor CXCR4 is required for outgrowth of colon carcinoma micrometastases. Cancer Res 63: 3833-3839, 2003.

8. Kim J, Takeuchi H, Lam ST, Turner RR, Wang HJ, Kuo C, Foshag L, Bilchik AJ and Hoon DS: Chemokine receptor CXCR4 expression in colorectal cancer patients increases the risk for recurrence and for poor survival. J Clin Oncol 23: 2744-2753, 2005 .

9. Kawada K, Hosogi H, Sonoshita M, Sakashita H, Manabe T, Shimahara Y, Sakai Y, Takabayashi A, Oshima M and Taketo MM: Chemokine receptor CXCR3 promotes colon cancer metastasis to lymph nodes. Oncogene 26: 4679-4688, 2007.

10. Zipin-Roitman A, Meshel T, Sagi-Assif O, Shalmon B, Avivi C, Pfeffer RM, Witz IP and Ben-Baruch A: CXCL10 promotes invasion-related properties in human colorectal carcinoma cells. Cancer Res 67: 3396-3405, 2007.

11. Cambien B, Karimdjee BF, Richard-Fiardo P, Bziouech H, Barthel R, Millet MA, Martini V, Birnbaum D, Scoazec JY, Abello J, et al: Organ-specific inhibition of metastatic colon carcinoma by CXCR3 antagonism. Br J Cancer 100: 1755-1764, 2009.

12. Kawada K and Taketo MM: Significance and mechanism of lymph node metastasis in cancer progression. Cancer Res 71: 1214-1218, 2011

13. Moffett JR and Namboodiri MA: Tryptophan and the immune response. Immunol Cell Biol 81: 247-265, 2003.

14. Yoshida R, Urade Y, Tokuda M and Hayaishi O: Induction of indoleamine 2,3-dioxygenase in mouse lung during virus infection. Proc Natl Acad Sci USA 76: 4084-4086, 1979.

15. Yoshida R and Hayaishi O: Induction of pulmonary indoleamine 2,3-dioxygenase by intraperitoneal injection of bacterial lipopolysaccharide. Proc Natl Acad Sci USA 75: 3998-4000, 1978.
16. Pfefferkorn ER: Interferon gamma blocks the growth of Toxoplasma gondii in human fibroblasts by inducing the host cells to degrade tryptophan. Proc Natl Acad Sci USA 81: 908-912, 1984

17. Théate I, van Baren N, Pilotte L, Moulin P, Larrieu P, Renauld JC, Hervé C, Gutierrez-Roelens I, Marbaix E, Sempoux C and Van den Eynde BJ: Extensive profiling of the expression of the indoleamine 2,3-dioxygenase 1 protein in normal and tumoral human tissues. Cancer Immunol Res 3: 161-172, 2015.

18. Munn DH, Zhou M, Attwood JT, Bondarev I, Conway SJ, Marshall B, Brown C and Mellor AL: Prevention of allogeneic fetal rejection by tryptophan catabolism. Science 281: 1191-1193, 1998.

19. Zou W: Immunosuppressive networks in the tumour environment and their therapeutic relevance. Nat Rev Cancer 5: 263-274, 2005.

20. Brandacher G, Perathoner A, Ladurner R, Schneeberger S, Obrist P, Winkler C, Werner ER, Werner-Felmayer G, Weiss HG, Göbel G, et al: Prognostic value of indoleamine 2,3-dioxygenase expression in colorectal cancer: Effect on tumor-infiltrating $\mathrm{T}$ cells. Clin Cancer Res 12: 1144-1151, 2006.

21. Ferdinande L, Decaestecker C, Verset L, Mathieu A, Moles Lopez X, Negulescu AM, Van Maerken T, Salmon I, Cuvelier CA and Demetter P: Clinicopathological significance of indoleamine 2,3-dioxygenase 1 expression in colorectal cancer. Br J Cancer 106: 141-147, 2012.

22. Gao YF, Peng RQ, Li J, Ding Y, Zhang X, Wu XJ, Pan ZZ, Wan DS, Zeng YX and Zhang XS: The paradoxical patterns of expression of indoleamine 2,3-dioxygenase in colon cancer. J Transl Med 7: 71, 2009.

23. Sedlmayr P, Blaschitz A, Wintersterger R, Semlitsch M, Hammer A, MacKenzie CR, Walcher W, Reich O, Takikawa O and Dohr G: Localization of indoleamine 2,3-dioxygenase in human female reproductive organs and the placenta. Mol Hum Reprod 8: 385-391, 2002.

24. Vandercappellen J, Van Damme J and Struyf S: The role of CXC chemokines and their receptors in cancer. Cancer Lett 267: 226-244, 2008.

25. Murakami T, Kawada K, Iwamoto M, Akagami M, Hida K, Nakanishi Y, Kanda K, Kawada M, Seno H, Taketo MM and Sakai Y: The role of CXCR3 and CXCR4 in colorectal cancer metastasis. Int J Cancer 132: 276-287, 2013.

26. Oliveira Frick V, Rubie C, Ghadjar P, Faust SK, Wagner M, Gräber S and Schilling MK: Changes in CXCL12/ CXCR4-chemokine expression during onset of colorectal malignancies. Tumour Biol 32: 189-196, 2011.

27. Fukunaga S, Maeda K, Noda E, Inoue T, Wada K and Hirakawa K: Association between expression of vascular endothelial growth factor $\mathrm{C}$, chemokine receptor CXCR4 and lymph node metastasis in colorectal cancer. Oncology 71: 204-211, 2006.

28. Gassmann P, Haier J, Schlüter K, Domikowsky B, Wendel C, Wiesner U, Kubitza R, Engers R, Schneider SW, Homey B and Müller A: CXCR4 regulates the early extravasation of metastatic tumor cells in vivo. Neoplasia 11: 651-661, 2009.

29. Sakai N, Yoshidome H, Shida T, Kimura F, Shimizu H, Ohtsuka M, Takeuchi D, Sakakibara M and Miyazaki M: CXCR4/CXCL12 expression profile is associated with tumor microenvironment and clinical outcome of liver metastases of colorectal cancer. Clin Exp Metastasis 29: 101-110, 2012.

30. Zhang NH, Li J, Li Y, Zhang XT, Liao WT, Zhang JY, Li R and Luo RC: Co-expression of CXCR4 and CD133 proteins is associated with poor prognosis in stage II-III colon cancer patients. Exp Ther Med 3: 973-982, 2012.

31. Li JK, Yu L, Shen Y, Zhou LS, Wang YC and Zhang JH: Inhibition of CXCR4 activity with AMD3100 decreases invasion of human colorectal cancer cells in vitro. World J Gastroenterol 14: 2308-2313, 2008

32. Uyttenhove C, Pilotte L, Théate I, Stroobant V, Colau D, Parmentier N, Boon T and Van den Eynde BJ: Evidence for a tumoral immune resistance mechanism based on tryptophan degradation by indoleamine 2,3-dioxygenase. Nat Med 9: 1269-1274, 2003

33. Muller AJ, DuHadaway JB, Donover PS, Sutanto-Ward E and Prendergast GC: Inhibition of indoleamine 2,3-dioxygenase, an immunoregulatory target of the cancer suppression gene Bin1, potentiates cancer chemotherapy. Nat Med 11: 312-319, 2005.

34. Okamoto A, Nikaido T, Ochiai K, Takakura S, Saito M, Aoki Y, Ishii N, Yanaihara N, Yamada K, Takikawa O, et al: Indoleamine 2,3-dioxygenase serves as a marker of poor prognosis in gene expression profiles of serous ovarian cancer cells. Clin Cancer Res 11: 6030-6039, 2005. 